\title{
Ei tverrfagleg tilnærming til scenespråk
}

Ragnhild Gjefsen

\begin{abstract}
This article explores a possible methodological framework for investigating verbal theatre language. Using an interdisciplinary approach, combining theatre studies with sociolinguistics, it is possible to increase knowledge about conventions and changes in Norwegian theatre language in the 20th century. I will demonstrate how sociolinguistics can provide a broader understanding of the development in Norwegian theatre, through investigating socially meaningful variation in theatre language.
\end{abstract}

Keywords: Theatre language, theatre history, conventions, sociolinguistics, Nationaltheatret, NRK

\section{Om forfattaren}

Ragnhild Gjefsen er stipendiat i Teatervitskap ved Institutt for lingvistiske, litterære og estetiske studium, Universitetet i Bergen. Ph.d.-prosjektet karakteriserer og ser på endringar i norsk munnleg scenespråk på 1900-talet. MA i Teatervitskap frå UiB (2012), ein av to kunstnariske leiarar i Frontlosjefestivalen, frilans skribent i Norsk Shakespearetidsskrift.

\section{Ragnhild.Gjefsen@uib.no}

Teatervitenskapelige studier 2019 (C) Ragnhild Gjefsen

Nummerredaktører: Siren Leirvåg, Ine Therese Berg, Rikke Gürgens-Gjærum og Ragnhild Tronstad.

For TVS: Siren Leirvåg, Ellen Karoline Gjervan og Ragnhild Gjefsen.

Ansvarlig redaktør: Tor Bastiansen Trolie - tor.trolie@,uib.no

Publisert av Teatervitenskap, Institutt for lingvistiske, litterære og estetiske studier, Universitetet i Bergen

Bergen Open Access Publishing - https://boap.uib.no/index.php/tvs

ISSN: 2535-7662

Artikkelen bygger på et innlegg fra konferansen Teatervitenskapelig dugnad i Bergen 2018.

Prosjektet er støttet av Norsk kulturråd. 


\section{Ei tverrfagleg tilnærming til scenespråk}

Denne artikkelen tek for seg sentrale aspekt $\mathrm{i}$ arbeidet mitt med å finne ein metodisk inngang til å undersøke scenespråk gjennom å kombinere to fagdisiplinar: teatervitskap og sosiolingvistikk. Eg vil hevde at ei slik kartlegging av det talte språket i teaterpraksisen - som undersøker scenespråket både på allment språkbruksnivå og i lys av teateret sine konvensjonar - kan hjelpe oss å forstå endringar over tid i scenespråk og skodespelarkunst i norsk teater. Forskingsprosjektet som er utgangspunkt for dette arbeidet, går inn for å karakterisere norsk scenespråk på 1900-talet. Der er målet å finne ut meir om kva konvensjonar som regulerer det og kva type variasjonar og stabile forhold i scenespråket det er mogleg å spore mellom ulike typar oppsettingar over tid. Prosjektet nyttar skodespelarar knytte til Nationaltheatret som døme, i produksjonar på scenen og i radioog fjernsynsteater. For å gi ei så substansiell skildring av scenespråket som mogleg vil eg legge vekt på å undersøke kva konvensjonar som styrer det, til dømes fiksjonelle, sosiale, språklege og estetiske. Desse formar scenespråket og korleis publikum oppfattar det.

I det følgjande vil eg gå nærmare inn på korleis eg kan nytte sosiolingvistikk som støttedisiplin i arbeidet med å karakterisere konvensjonar i det norske scenespråket. Gjennom å ta i bruk språkvitskapelege metodar vil eg få eit breiare empirisk materiale å jobbe ut frå, samt metodiske inngangar som styrkar dei systematiske og analytiske innfallsvinklane teatervitskapen alt har til rådigheit. Vidare har det vorte tydeleg for meg at teatersemiotikk vil kunne fungere som ei metodisk ramme for samverknaden mellom dei to fagområda.

\section{Motivasjonen bak ein tverrfagleg metode}

Tverrfaglegheit slik vi definerer det i dag oppsto med dei moderne vitskapelege disiplinane rundt førre hundreårskiftet (Turner i Frodeman, Klein og Pacheco, 2017, s. 9). Men praksisen er ikkje ny, og i dei fleste humanistiske fag er det allereie ei ibuande tverrfaglegheit, der dei enkelte disiplinane undersøker samansette fenomen og tek inn over seg kompleksiteten i sine forskingsobjekt (Krohn i Frodeman, Klein og Mitcham, 2010, s. 33). Dette gjelder til dømes for sosiolingvistikken, som oppsto ved at ein kombinerte perspektiv frå lingvistikk med sosiologi for betre å forstå språk som eit sosialt mellommenneskelig fenomen (Romaine, 2000, s. IX). Det gjeld òg i høgste grad for teatervitskapen, sidan teaterkunsten har ein klar tverrestetisk karakter i seg. I tillegg har det tverrfaglege i dei seinare åra kome sterkare fram gjennom kunstnariske praksisar, mellom anna på grunn av ein auka tendens til sjangeroverskriding mellom teater og til dømes performance eller installasjonskunst (Augsburg i Frodeman, Klein og Pacheco, 2017, s. 132). Og sidan forskingsobjektet er så samansett, slår tverrfaglegheita inn også i teori- og metodevala. Eit døme på dette er framsyningsanalysen, som kan nytte element frå felt som antropologi, semiotikk, sosiologi og kulturvitskap i sin søken etter å analysere teaterhendinga som heile. 
I ei undersøking av scenespråk kjem behovet for og fordelane ved ei tverrfagleg tilnærming fram. Ulike typar forsking på talespråk vil vere relatert til kvarandre, anten det er snakk om scenespråk eller daglegtale. Kombinasjonen av teatervitskap og sosiolingvistikk vil med sine innfallsvinklar kunne utfylle kvarandre $\mathrm{i}$ arbeidet med å gjere ei inngåande karakterisering og skildring av talespråket i teateret. Dette er dels fordi faga til saman dekkjer eit litt større felt av kva som alt er undersøkt, som eg kan dra nytte av, og dels fordi det let meg undersøke språket frå fleire vinklar.

Det er i liten grad gjort vitskapelege undersøkingar av korleis norsk scenespråk høyres ut. I teatervitskapelege og teaterhistoriske studium har fokuset ofte vore på andre framsyningselement enn det talte språket. Den teatervitskapelege forskinga på scenespråk på teoretiske og praktiske plan i mellom anna teatersemiotikk (Fischer-Lichte, 1983; Holm, 1981; Drozd, Kačer og Sparling, 2016) og skodespelarteori (Larsen, 1917; Trolie, 2005a, b; Strömberg, 2011) er arbeid som alle peiker mot, men ikkje dekker det området eg ønskjer å skildre.

Vidare er det som blir sagt på teaterscena, eit planlagt språk som fell mellom to stolar i lingvistikken, der ein gjerne konsentrerer seg om anten skrift eller naturleg tale. For sjølv om teateret i høve til naturlegheits- og realismekonvensjonar søkjer å verke naturleg, er det ikkje eit kvardagstalemål skodespelarane presenterer. Scenespråket må til dømes vere tydeleg og forståeleg for eit publikum, og er som regel planlagt og innøvd for å verke truverdig og naturleg. I sosiolingvistikken ligg fokuset på talemålet i relasjon til den sosiale funksjonen det har, sjeldan på studiet rundt mediet språket blir presentert i. Slik bryt teateret som medium den direkte koplinga mellom talemål og samfunn, og det er i dette mellomstadiet eg ønskjer å gjere mine undersøkingar.

Når eg skal behandle lydmaterialet ${ }^{1}$ eg har valt ut i prosjektet, tek eg fatt på det som ein framsyningsanalyse kor eg forsøker å fange opp dei spesifikke teatermessige forholda som påverkar språket i overgangen til scena: dramatisk tekst eller dramatisk univers, teaterrommets auditive forhold, estetisk deklamatoriske tradisjonar (stemmebruk og utdanning). Her har eg alt verktøy for å finne mange moment og tendensar som eg kan sette saman til eit heilskapsinntrykk, men eg har ikkje alltid ein god måte å forklare dei språklege fenomena på. Derfor meiner eg det er nyttig å hente metodiske grep og teori frå sosiolingvistikken for å forstå meir om mekanismar i språket. Eg vil kunne nytte presise fagtermar, og eg kan støtte meg på ein velutvikla metode for å kartlegge endringar i språk. Dette kan eg igjen sette i samanheng med teaterspesifikke forhold og premiss som tek høgde for det estetiske. Ei tverrfagleg tilnærming opnar dermed for ei breiare systematisk skildring av scenespråket som scenisk teatral uttrykksform - eit arbeid som vil kunne bidra til både teater- og språkhistorie.

\section{Metodeval som kommuniserer}

Sosiolingvistikk har gode systematiske metodar som går spesifikt på talespråk, og vil derfor vere til stor hjelp for å peike på kva som skjer reint språkleg på teaterscenen. Men skal eg integrere språklege funn i det teatervitskaplege arbeidet vil det ikkje vere tilstrekkeleg å låne med seg

\footnotetext{
${ }^{1}$ Eit utval lydopptak gjort av framsyningar på Nationaltheatret, NRK Radioteateret og NRK Fjernsynsteateret i perioden 1937-1999. Eg vil konsentrere meg om scenespråket til skodespelarar knytte til Nationaltheatret også i dei to sistnemnte.
} 
omgrep frå sosiolingvistikken, på same måte som det ikkje vil vere tilstrekkeleg å nytte sosiolingvistisk metode når eg òg ønskjer å fange opp den kunstnariske sida ved scenespråket. Vidare vil det heller ikkje vere gunstig å la to ulike innfallsvinklar stå for seg - dei må kunne fungere i lag. Derfor er det eit mål å finne eit systematisk utgangspunkt for framsyningsanalysen som «snakkar» godt med sosiolingvistikken.

Ein slik teatervitskapleg metodisk inngang kan vere teatersemiotikken, som òg er det teoretiske og metodiske området innanfor teatervitskap som har kome lengst i å systematisk skildre scenespråket. Den ser på framsyninga som eit system av teatrale teikn i stadig rørsle, og synleggjer kva kodar og konvensjonar som regulerer bruken og tydinga av teikn i teateret (Fischer-Lichte, 1983, s. 21). Heller enn å ta utgangspunkt i den dramatiske teksten blir det talte scenespråket behandla som auditive teikn hos aktøren (Aston og Savona, 1991, s. 105-106). Dette gjer det mogleg å gå spesifikt inn på akustiske, lingvistiske og paralingvistiske teikn framført av skodespelaren (Fischer-Lichte, 1983, s. 28; Kowzan, 1981, s. 61). Ved hjelp av semiotiske verktøy kan eg i framsyningsanalysen vektlegge korleis ulike språklege element kan kommunisere meirtyding (konnotasjon) når dei blir sett i scenisk og dramatisk relasjon til kvarandre - ut over den direkte (denotative) meininga i det enkelte ordet og den enkelte setninga. I det å fokusere på korleis scenespråket kommuniserer ved hjelp av teikn og kodar ligg det eit potensial for å avdekke og forklare dei bestemte teaterkonvensjonane.

Teatersemiotikken er i seg sjølv utvikla i eit tverrfagleg perspektiv (De Marinis, 1993, s. 7) og tilbyr eit omgrepsapparat som til ei viss grad er felles for dei to disiplinane. Slik kan metoden vere eit nyttig verktøy for å kategorisere språklege element i ei framsyning, og samstundes gjere det enklare å integrere lingvistiske aspekt i det teatervitskapelege analysearbeidet. I sosiolingvistikk ser ein til dømes på korleis språket kommuniserer gjennom val av stil og stilisering, og korleis gitte språktrekk og ordval kan få meining i bestemte kombinasjonar (t.d. i Eckert, 2016). Denne metoden i sosiolingvistikk liknar mykje på måten ein undersøker kommunikasjonsaspektet i teateret på, og verkar vere eit naturleg bindeledd mellom dei to tilnærmingane til scenespråket. Ved å sjå på kommunikative sider ved den språklege forma vil eg òg kunne gå vidare og skile mellom ålmenne og teatrale kodar, og peike på når og korleis dei ålmenne sosiale kodane blir nytta som teaterkonvensjonar. Det å nytte sosiolingvistikk som støttedisiplin vil gi meg fleire metodiske fordelar i analysen, der ein annan av desse er moglegheita for kartlegginga av språklege endringar over tid.

\section{Kartlegging av endring gjennom variasjon}

Eit grunnleggande trekk ved sosiolingvistiske studium har vore interessa for å finne variasjonar i talemål over tid (Romaine, 2000, s. 135-136). Arbeidet med å undersøke kva som er stabilt, og kva som endrar seg, kan ein gjere gjennom å sjå etter gitte variablar i eit språksamfunn. Eit slikt variasjonsstudium er det òg naturleg å nytte som hovudinngang for å sjå på scenespråket, sjølv om påverknaden frå manuset som ligg til grunn, gjer det vanskelegare å peike på konsekvente variasjonar over tid.

Eg ønskjer å undersøke språktrekk som leksikalske forandringar (nu > nå, meget $>$ mye), pragmatiske ord (De vs. du, sivile titlar og yrkestitlar), teljemåte (fireogtyve $>$ tjuefire), uttale av 
konsonantar og vokalar (stum d, tjukk l, fremre a etc.) og suprasegmentale trekk (trykkplassering og samantrekkingar). Dokumentasjon av førekomsten til denne typen variablar vil hjelpe meg å finne ut korleis scenespråket står i høve til samtidig daglegtale, kva dialektar som dominerer eller kva for språklege og stilistiske skilnadar eg finn mellom oppsettingar basert på klassisk dramatikk og dei som brukar samtidsdramatikk. Da kan eg til dømes gå inn i ei framsyning frå 1930-talet, som Et dukkehjem (NRK, 1939) og registrere at variablar som «nu» (leksikalsk variant $\mathrm{i}$ bokmålsrettskriving) og «kvidre» (lenisering, eller såkalla blaute konsonantar) er i aktiv bruk, det same er høfleg tiltale (pragmatiske ord). Vidare vil eg sjå nærmare på bestemte val av uttale, sidan språklydane sin kvalitet er sentralt for korleis vi opplever språk. Her vil det vere nyttig å ha eit sideblikk på kva metodar som finst for å granske prosodisk variasjon (det vil seie trykk, tonelag, lengde, styrke og setningsmelodi). Sidan dette er trekk som kan vere vanskelegare å identifisere enn dei nemnte variablane, vil det vere viktig å definere språktrekka opp mot mine undersøkingar, med klare rammar for kva eg registrerer.

For å gje dei sosiolingvistiske funna teatervitskapleg meining vil det vere naudsynt å sette dei i samanheng med teaterhistoriske og teaterspesifikke forhold og premiss, i forsøket på å skildre scenespråket og kva for konvensjonar som regulerer det. Når ein skal sjå på scenespråk over tid, vil det heller ikkje vere nok å ta for seg enkelte ord og uttaleformar for å sjå om dei endrar seg. For sjølv om ulike iscenesettingar held på ordlyden, er det likevel lett å høyre at noko i dialogen har endra seg - spelestil og iscenesettingsstil kjem til uttrykk i språket. Korleis kan eg til dømes fange opp og skildre at dialogen mellom Nora og Torvald i Et dukkehjem endrar seg over tid? Orda og uttala kan vere den same, men det kan vere endringar i korleis til dømes kjensler kjem til uttrykk gjennom det lydmessige. Ein del av det å karakterisere scenespråket er å sjå på korleis det er noko anna enn daglegtale, og da er det ikkje nok å påpeike gitte språklege variablar.

\section{Teatrale språktrekk}

I arbeidet treng eg òg å inkludere dei delane av språket som har spesifikk teatral og dramatisk funksjon: element nytta som verkemiddel i framstillinga av karakter, kjensler, sinnsstemning, status og maktforhold med meir - som igjen gir informasjon om teaterkonvensjonar. Eg vil òg sjå til skodespelarteknikk og stemmeteknikk, og registrere korleis skodespelarane nyttar verkemiddel som stemmeleie, melodi, frasering, pausering, pust og vibrato - som ein i teatersemiotikken omtalar som paralingvistiske trekk (Fischer-Lichte 1983, s. 38).

I radioteateroppsettinga av Et dukkehjem (NRK, 1971) kan eg til dømes registrere korleis Nora framleis nyttar «nu» som variabel i staden for «nå». Men eg kan òg registrere korleis pust blir nytta mot slutten av kvar setning for å understreke intensitet og kjensler. I 1939-varianten finn eg ikkje dette trekket, men heller auke i volum, stemmeleie og tempo. Dette kan vise seg å vere eit teikn på at konvensjonen for korleis ein framstiller psykologisk intensitet gjennom scenespråket har endra seg. Det same har tonehøgda, og det lyse målet til Nora anno 1939 kan vere eit resultat av samtidas feminine ideal - toneleie i teateret blir gjerne påverka av trendar (Martin, 1991, s. 39).

Denne typen paralingvistiske trekk hjelp oss til dømes å dekode fråsegna så vi forstår om ein person er trist eller ironisk. Det rommar òg stemmemessige trekk som ofte ikkje er meint å vere tydingsbærande, men som kan bli tolka som teikn av ein mottakar, til dømes trekk som gir 
opplysningar om kjønn og alder (Fischer-Lichte, 1983, s. 38-39). Noko liknande ser vi i dømet over, der bruken av pust kommuniserer kjensler. I teateret vil dette alltid vere medvitne uttrykk, i kraft av at aktøren på scena framstiller ein annan karakter enn seg sjølv. I det publikum aksepterer konvensjonane $\mathrm{i}$ iscenesettinga, blir kvar del av den verda som er ramma inn, tydingsfull (Eco, 1981, s. 33). Slike prosodiske og paralingvistiske trekk vil derfor vere relevante å ha med i ei skildring av scenespråket.

\section{Å sette funna i kontekst}

Når eg har samla inn dei språklege variablane og trekka, vil neste trinn vere å vurdere kva verdi desse har - på same måte som vi har sett på i døme med pusten til Nora i oppsettinga i 1970. Men kva vil det seie at ho nyttar variablar som «nu» og «efter»? Dette er eldre variabelvariantar både munnleg og skriftleg; «etten og «nå» har vore formelle rettskrivingsformer sidan 1938. Her kan verdien av orda vere at dei er gamle eller konservative. Det kan tyde på at fiksjonen er lagt til gamledagar, men også at personen som snakkar, er eldre eller konservativ. Her må eg sette variabelvalet inn i ein større kontekst og sjå på kva konvensjonar som speler inn. I tilfellet med radioteateroppsettinga av Et dukkehjem (NRK) frå 1971 handlar ordvalet nok om at fiksjonen er lagt attende i tid. Dette blir tydeleg fordi dei òg tek i bruk ord som «spesidaler», ein eldre valutaform. Men samstundes har dei latt ordet «kvartal» erstatte «fjerdingår», som er å finne i ei eldre radioinnspeling av same stykke (NRK, 1953). Orsaka til at dei ikkje har behaldt alle dei eldre formane, ligg nok i at det ville ha blitt oppfatta som kunstig og rart i samtida. Kva språktrekk ein vel å legge inn frå ein annan tidsperiode og kva ein vel å behalde i ei moderne språkdrakt er ei avgjerd basert på kva ein trur publikum vil forstå.

Denne typen verdivurdering av variablar er ikkje berre aktuell frå eit språkvitskapleg perspektiv, det er òg ei tilnærming som er relevant for teatervitskapen. Ei framsyning er frå eit semiotisk perspektiv sett saman av ei rekke teikn, regulert av kodar og konvensjonar. Her blir konvensjonar forstått som «[...] en egen og specifik type av koder, som accepteres af deltagerne i en forestillingshændelse og derved kommer til at virke sammen med og ind på mangfoldet af almene koder, som deltagerne benytter sig af under forestillingen» (Hyldig, 2000, s. 17). Det er med andre ord snakk om alle dei eksplisitte og implisitte føresetnadene som trengs for å gjere publikum innforstått med den scenisk-dramatiske fiksjonen (Pavis, 1998, s. 78), altså fiksjonskontrakten. Ein spaserstokk kan vere nøkkelen til at ein karakter blir oppfatta som gammal, og delar av eit tre i scenografien kan vere nok til at vi forstår at handlinga går føre seg ute i naturen - utan at det er naudsynt å plassere heile skogen på scena. På same måte som vi berre treng nokre få visuelle indikasjonar på at fiksjonen er lagt til ein skog, kan enkelte språklege teikn gi oss nøkkelen til å utløyse ein bestemt fiksjonskonvensjon. I dag vil til dømes bruk av høfleg tiltale gi inntrykk av at handlinga er lagt attende i tid. Men variablane kan gi oss langt meir informasjon enn berre å tidfeste den dramatiske fiksjonen. Gjennom verdivurdering av variablar kan eg òg hente ut informasjon om sosiale og kulturelle forhold hos karakterane. 


\section{Språkleg stilisering og forsking på mediespråk}

I samanheng med denne typen verdivurdering av variablar vil eg ha god nytte av studium gjort på tala media, særleg radio og tv, som utgjer ein sentral del av språkkvardagen vår. Det er ein stad der kulturelle normer og stilar blir reflektert, spreidd og forsterka (Mortensen, Coupland og Thøgesen, 2017, s. 8). I sosiolingvistisk forsking på media ligg fokuset ofte på å undersøke i kva grad radio og tv påverkar daglegtalen, og om det er i retning av eit normert språk (Thøgesen, 2016, s. 105-106). Som ein del av dette arbeidet ser ein mellom anna på ulike stilar og ålmenne konvensjonar innanfor delvis planlagt språk i talemedia. Dette vil det vere mogleg å overføre til ein studie av det planlagde scenespråket, sjølv om fokuset i mitt tilfelle vil ligge på karakteriseringa av språket i seg sjølv og i mindre på grad korleis det påverkar talemålet til publikum. Det å ta utgangspunkt i denne typen nyare studiar innanfor sosiolingvistikk (Nesse, 2014; Mortensen et al., 2017; Thøgesen et al., 2016) ser ut til å vere ein nøkkel for å kople metodisk innsikt frå språkvitskapen med teatervitskapelege forhold.

Da er eg spesielt interessert i det sosiolingvistiske konseptet «stil», som gjennomgåande i denne artikkelen er meint som dei språklege tilpassingane vi gjer i sosiale situasjonar. I media bruker ein stilisering medvite for å bli oppfatta på ein bestemt måte, til dømes som seriøs eller folkelig. Denne typen stil orienterer seg etter kva som er norma i ein gitt bruk av språk eller dynamisk konstruert i gitte kontekstar (Mortensen, Coupland og Thøgesen, 2017, s. 1). Mange variablar i språket er sosialt meiningsbærande og fungerer som stilistiske komponentar, der variasjon i val og kombinasjon av desse er med på å formidle informasjon om språkbrukaren (Eckert, 2016, s. 70). Slike sosiolingvistiske variasjonar utgjer eit teiknsystem som kontinuerlig gir sosiale opplysningar utan at det er naudsynt å uttrykke dei med ord (Eckert, 2016, s. 68).

Eit døme på ein slik studie gjort på talt mediespråk er «The style and stylization of old news reading in Danish» (Thøgesen, 2016), ein analyse av eit satirisk radioinnslag i Ugereryen på dansk P1. I dette faste innslaget prøver dei å oppnå effekten av 1930- og 40-tals filmaviser gjennom språkbruk og lydeffektar. Språkforskaren Jacob Thøgesen har i sin studie analysert kva språkleg stilisering aktørane nyttar for å verke gammaldagse, noko han referer til som «old news style» eller berre «old style» (Thøgesen, 2016, s. 107). Med tanke på mitt arbeid er dette interessant fordi det er eit døme som syner korleis ein språkleg stil kan formidle dei same sosiale opplysingane (ha same indeksikale verdi) sjølv om variablane i stilen endrar seg over tid, og korleis dette kan bli eit nytta som eit medvitent verkemiddel: Det som på fyrste halvdel av 1900-talet vart oppfatta som seriøst og formelt, vil i dag bli sett på som så hyper-formelt at det får ein komisk effekt (ibid.). Thøgesen viser korleis satiren reint språkleg klarer å oppnå denne gammaldagse effekten, og gjer i tillegg greie for fonologiske endringar over tid i danske radionyheiter i form av ein kvantitativ analyse av utvalde språklege variablar, mellom anna ulike uttalar av $a$. Dette viser korleis ein stil som blir oppfatta som seriøs og formell, gradvis har endra seg over tid (Thøgesen, 2016).

I denne typen forsking ser eg fleire metodiske grep som kan overførast til ei undersøking av scenespråk, der kombinasjonen av kvantitative undersøkingar og ein meir generell analyse opnar for at eg både kan karakterisere scenespråket og vise korleis det endrar seg over tid. Den sosiolingvistiske innfallsvinkelen har fleire fellestrekk med ei framsyningsanalyse og vil vere eit godt supplement til det teatervitskapelege arbeidet. Og frå eit teaterperspektiv kan eg sjå på enda 
fleire moment som speler inn på scenespråket: I tillegg til ei sosiolingvistisk stilanalyse vil eg sjå på korleis kjensler blir framstilt, men òg vere obs på korleis både tekstleg og scenisk dramaturgi kan påverke stilval. Eit døme på dette er passasjer av typen ein finn i Gengangere, der Pastor Manders går bort frå den gjennomgåande høflege forma og omtalar fru Alving som «Helene» i slutten av 1. akt (Ibsen, 2005, s. 114). Slike språklege grep gjer meir enn å plassere karakterane i eit gitt sosialt lag, det endrar òg den dramaturgiske dynamikken i framsyninga.

Dette opnar opp for å peike på korleis stilval og formgrep i scenespråket er medvite utforma og korleis ulike sosiale aspekt blir framstilt språkleg i framsyninga. Det gjer det òg enklare å kartlegge korleis samfunnsmessige stereotypar blir framstilt i teateret i ulike periodar. Dersom det til dømes er tydeleg stilistisk skilnad mellom korleis Nora Helmer og barnepiken Anne-Marie snakkar i ei oppsetting av Et dukkehjem, vil dette signalisere den sosiale posisjonen mellom dei to utan at publikum treng å få det eksplisitt forklart. Dette speglar teatersemiotikken sitt syn på korleis kombinasjonen av teikn i teaterframsyninga kan kommunisere gitte konnotasjonar.

Stilisering kan hjelpe meg å avdekke konvensjonar over tid, noko eg ser som sentralt for å forstå den kunstnariske dimensjonen i scenespråket, mellom anna i høve til norma at det skal verke naturleg i den utvalde perioden og i den spesifikke framsyninga. Det hjelp meg å sette ord på korleis stilval og formgrep i scenespråket er bevisst utforma og trekk inn sosiale og kommunikative sider ved den språklege forma.

\section{Eit fruktbart møte}

Gjennom arbeidet med å finne ein metode for å studere norsk scenespråk blir det tydeleg korleis sosiolingvistikk kan bidra til teatervitskapen gjennom djupgåande og spesifikke kunnskapar om språk. Den tverrfaglege tilnærminga mellom teatervitskap og sosiolingvistikk finn motivasjonar frå fleire hold - både som konkret problemløysar i møte med scenespråket og som eit ledd i den naturlege utviklinga fagområda har hatt dei seinare åra, mellom anna innanfor sosiolingvistiske studium som omhandlar media og stilisering. På same måte som eg som teatervitar finn det naturleg å søke til desse områda i språkvitskapen fordi dei nærmar seg planlagt språk, ser eg korleis mitt innleiande val av støttedisiplin har påverka slutninga om å nytte teatersemiotikk - eit metodisk rammeverk som gjer samspelet mellom dei to disiplinane meir saumlaust.

Teatersemiotikk vil hjelpe meg å skildre korleis forma til scenespråket er, òg når det kjem til å karakterisere og systematisere paralingvistiske sider ved språket. Ein tydeleg fordel ved å nytte teatersemiotikk i eit studie av scenespråk er at det er eit system spesielt utvikla for og mynta på teateret. Den behandlar språket som ein integrert del av framsyninga og legg til rette for analyse av kva kunstnariske element som pregar språket. Men her ligg òg avgrensinga: Det er eit system som famnar alle elementa i teateret, og går derfor ikkje i djupna på det språklege aspektet spesielt. Systemet kan berre delvis gi meg det eg treng for å spore endringar over tid, og det er ikkje eit verktøy som gjer det mogleg for meg å undersøke i kva grad scenespråket speglar daglegtale.

Det kan derimot variabelstudiar gjere, og ved hjelp av sosiolingvistikk kan eg ta eit steg lenger i arbeidet med å gi ei karakterisering av kva som skjer reint språkleg. Gjennom å identifisere språkkodene er det enklare å avdekke kva som er knytt til meir samfunnsmessige normer og kvar 
dei kunstnariske konvensjonane trer inn - meint som det ekstra settet med kodar som bli lagt til språket og gjer det til eit scenespråk. Det gir meg eit sterkare empirisk grunnlag eg kan basere analysane mine på.

Sosiolingvistikken vil òg ytterlegare komplementere analysearbeidet gjennom å sjå sosiale og kommunikative sider ved den språklege forma som semiotisk meiningsbærande. Her ser eg òg potensial for at kunnskap frå mitt fagfelt kan supplere sosiolingvistikken. Som teatervitar utvidar eg metoden for å sjå på det som blir formidla mellom orda, også i høve til kjensler og dynamikk, noko som kan vere med på å gjere undersøkinga av det språklege stilomgrepet meir omfattande. Den sosiolingvistiske forståinga av stilisering kan i kombinasjon med teatersemiotikk hjelpe meg å avdekke konvensjonar og konvensjonsendringar over tid, noko eg ser som sentralt for å forstå den kunstnariske dimensjonen i scenespråket, mellom anna i høve til norma om at det skal verke naturleg. I kombinasjon vil dei to disiplinane kunne gi både eit breiare bilete og ei djupare forståing av norsk scenespråk. 


\section{Bibliografi}

Aston, E. og Savona, G. (1991). Theatre as sign-system: a semiotics of text and performance. London: Routledge.

De Marinis, M. (1993). The semiotics of performance. Bloomington: Indiana University Press.

Drozd, D., Kačer, T. og Sparling, T. (red.) (2016). Theatre theory reader: Prague school writings. Praha: Karolinum Press.

Eckert, P. (2016). Variation, meaning and social change, i Coupland, N. (red.) Sociolinguistics : Theoretical Debates. Cambridge: Cambridge University Press, s. 68-85.

Eco, U. (1981). Teaterföreställningens semiotik, i Holm, I. (red.) Teater: en antologi: 2: Tecken, språk, struktur. Lund: Studentlitteratur, s. 27-38.

Fischer-Lichte, E. (1983). Semiotik des Theaters: eine Einfübrung: 1: Das System der theatralischen Zeichen. Vol. 1. Tübingen: Gunter Narr.

Frodeman, R., Klein, J. T. og Mitcham, C. (red.) (2010). The Oxford handbook of interdisciplinarity. Oxford: Oxford University Press.

Frodeman, R., Klein, J. T. og Pacheco, R. C. S. (red.) (2017). The Oxford Handbook of Interdisciplinarity, Second Edition. Oxford: Oxford University Press.

Holm, I. (red.) (1981). Teater: en antologi: 2: Tecken, språk, struktur. Lund: Studentlitteratur.

Hyldig, K. (2000). Realisme, symbol og psykologi : norsk Ibsen-tradition belyst gennem udvalgte forestillinger på Nationaltheatret 1899-1940. Doktorgrad. Bergen: Universitetet i Bergen.

Ibsen, H. (2005). Ibsen: samlede verker: 3: 1877-1899. Jubileumsutg. Vol. 3. Oslo: Kagge.

Kowzan, T. (1981). I teatertecknens universum, i Holm, I. (red.) Teater: en antologi: 2: Tecken, språk, struktur. Lund: Studentlitteratur. s. 47-63.

Larsen, T. (1917). Scenisk kunst: hvad enbver teaterinteresseret bor vide. København: Nyt Nordisk Forlag.

Martin, J. (1991). Voice in modern theatre. London: Routledge.

Mortensen, J., Coupland, N. og Thøgesen, J.(red.) (2017). Style, Mediation and Change: Sociolinguistic Perspectives on Talking Media. Oxford: Oxford University Press.

Nesse, A. (2014). Lyden av Norge. Språklig desentralisering og nasjonsbygging i NRK Radio, i Østerhaug, T. (red.) Arr: idébistorisk tidsskrift, 26/1, s. 83-95.

NRK. 1939. Et dukkebjem. NRK Radioteateret. Tilgjengeleg i Nasjonalbiblioteket sin database: https://www.nb.no/nbsok/nb/39a017b5f9864ac5b349d09daecaea5d?index=7 (avgrensa tilgang).

NRK. 1953. Et dukkehjem. NRK Radioteateret. Tilgjengeleg i Nasjonalbiblioteket sin database: https://www.nb.no/nbsok/nb/b04a68f5877a59514fe5bf89d04c81c4?index=100, del 1 (avgrensa tilgang). 
NRK. 1971. Et dukkebjem. NRK Radioteateret. Tilgjengeleg i Nasjonalbiblioteket sin database: https://www.nb.no/nbsok/nb/be276acfb4f23ac35f38a5f94e299755?index =2 (avgrensa tilgang).

Pavis, P. (1998). Dictionary of the theatre: terms, concepts and analysis, Dictionnaire du théatre. Toronto: University of Toronto Press.

Romaine, S. (2000.) Language in Society: An Introduction to Sociolinguistics. 2. utg. Oxford: OUP Oxford.

Strömberg, M. (2011). Fenomenet röst. Doktorgrad. Institutionen för musik- och teatervetenskapliga studier, Stockholms universitet.

Thøgesen, J. (2016). The style and stylization of old news reading in Danish, i Thøgesen, J., Coupland, N. og Mortensen, J. (red.) Style, Media and Language Ideologies. Vol. 3, Standard language ideologies in contemporary Europe. Oslo: Novus Press. s. 105-133.

Thøgesen, J., Coupland, N. og Mortensen, J. (red.) (2016). Style, Media and Language Ideologies. Vol. 3, Standard language ideologies in contemporary Europe. Oslo: Novus Press.

Trolie, T.B. (2005a). Fra sublim kunst til konseptkunst: skuespillerkunst 1750-2005, i Teatervitenskapelige studier.Vol. nr 7. Bergen: Universitetet i Bergen, Institutt for kulturstudier og kunsthistorie, Seksjon for teatervitenskap.

Trolie, T.B. (2005b). Skuespillerkunst i kontekst: En skisse til en vitenskapsteoretisk praksis, Studia Humanitatis Bergensia. Kristiansand: Høyskoleforlaget AS. 